\title{
EFEK TERAPI BRONKODILATOR DAN KORTIKOSTEROID TERHADAP PERUBAHAN NILAI ARUS PUNCAK EKSPIRASI (APE) PASIEN PENYAKIT PARU OBSTRUKTIF KRONIK (PPOK)
}

\author{
Putu Rika Veryanti ${ }^{1, *}$ dan I Dewa Gede Wisesa Budiman ${ }^{2}$ \\ ${ }^{1,2}$ Program Studi Farmasi, Fakultas Farmasi, Institut Sains dan Teknologi Nasional, Jakarta, \\ Indonesia \\ Email: *rika_veryanti@istn.ac.id \\ * corresponding author
}

\begin{abstract}
Abstrak
Penyakit paru obstruktif kronik (PPOK) adalah gangguan yang terjadi pada saluran pernapasan, yang ditandai dengan adanya penyempitan, hambatan aliran pada jalan napas dan bersifat kronik sehingga menyebabkan sesak. Bronkodilator dan kortikosteroid merupakan terapi lini pertama untuk pasien PPOK. Tatalaksana terapi yang tepat dan efektif dapat menurunkan angka morbiditas dan mortalitas PPOK. Namun, masih ditemui adanya permasalahan terkait efektivitas terapi pada pasien PPOK yang dirawat di rumah sakit. Salah satu parameter penting yang perlu dimonitoring pada pasien PPOK adalah arus puncak ekspirasi (APE). Tujuan dari penelitian ini adalah untuk mengetahui efek penggunaan bronkodilator dan kortikosteroid terhadap perubahan nilai APE pasien PPOK. Penelitian ini dilakukan di RSUP Persahabatan Jakarta dengan desain studi crosssectional. Sampel yang digunakan dalam penelitian ini adalah rekam medik pasien periode tahun 2018 dengan kriteria inklusi: pasien didiagnosa PPOK, mendapatkan terapi bronkodilator dan kortikosteroid serta memiliki data APE yang lengkap. Jumlah sampel sebanyak 99 dan ditentukan melalui purposive sampling. Data yang diperoleh selanjutnya dianalisis secara statistik dengan menggunakan uji t-berpasangan. Hasil penelitian menunjukkan bahwa terapi bronkodilator dan kortikosteroid dapat meningkatkan nilai APE pasien PPOK sebesar $(49,85 \pm 43,61) \mathrm{L} /$ menit atau $(46,05 \pm 51,15) \%$. Sebanyak 94,95\% pasien mengalami peningkatan nilai APE dan sebanyak $73,74 \%$ megalami peningkatan APE $\geq 15 \%$. Terapi bronkodilator dan kortikosteroid memiliki efek yang signifikan terhadap perubahan nilai arus puncak ekspirasi (APE) pasien PPOK $(p=0,000)$.

Kata kunci: Bronkodilator; Kortikosteroid; Arus Puncak Ekspirasi (APE); Penyakit Paru

Obstruktif Kronik (PPOK)
\end{abstract}

\begin{abstract}
Chronic obstructive pulmonary disease (COPD) is a disorder that occurs in the respiratory tract, which is characterized by narrowing, chronic obstruction of airway flow and causing shortness of breath. Bronchodilators and corticosteroids are the first-line therapy for COPD. Appropriate and effective therapeutic management can reduce COPD morbidity and mortality. However, we still found some problems related to the effectiveness of therapy in hospitalized COPD patients. One of the important parameters that need to be monitored in COPD patients is the peak expiratory flow. The purpose of this study was to determine the effect of the use of bronchodilators and corticosteroids on the peak expiratory flow value of COPD patients. This research was conducted at Persahabatan Hospital Jakarta with a cross-sectional study design. The sample that used in this study was patient medical records for the period 2018. The inclusion criteria were patient who
\end{abstract}


diagnosed with COPD, received bronchodilator and corticosteroid therapy and had complete peak expiratory flow value. The number of samples is 99 and determined through purposive sampling. The data were analyzed statistically using paired t-test. The results of this study showed that bronchodilator and corticosteroid therapy could increase the peak expiratory flow value of COPD patients by (49.85 \pm 43.61$) \mathrm{L} /$ minute or $(46.05 \pm 51.15) \%$. A total of $94.95 \%$ of patients experienced an increase in peak expiratory flow values and $73.74 \%$ patients had an increase in peak expiratory flow $\geq 15 \%$. Bronchodilator and corticosteroids had a significant effect on the peak expiratory current in COPD patients $(p=0.000)$.

Keywords: Bronchodilators, corticosteroids, peak expiratory flow, Chronic obstructive pulmonary disease (COPD)

\section{Pendahuluan}

Penyakit paru obstruktif kronik (PPOK) merupakan penyakit yang umumnya dapat dicegah dan diobati. PPOK dikarakterisasi dengan adanya hambatan aliran udara pada saluran napas dan atau disertai abnormalitas alveolar (Global Initiative for Chronic Obstructive Lung Disease, 2021). Hambatan aliran udara ini bersifat progresif dan dapat memburuk sehingga menyebabkan terjadinya gagal napas dan kematian. Angka kematian akibat PPOK di dunia terus mengalami peningkatan dan diprediksi akan menduduki peringkat tiga besar setelah jantung koroner dan stroke. Di Indonesia sendiri, prevalensi PPOK mencapai 3,7\% dan didominasi oleh laki-laki (Kementerian Kesehatan RI, 2013).

Salah satu upaya yang dapat dilakukan untuk mengurangi angka kematian pasien PPOK yang mengalami eksaserbasi adalah dengan penanganan dan pemberian terapi yang tepat. Bronkodilator dan kortikosteroid merupakan terapi pilihan pertama untuk pasien PPOK yang mengalami eksaserbasi akut atau yang membutuhkan perawatan di rumah sakit (Perhimpunan Dokter Paru Indonesia, 2011). Perbaikan kondisi pasien bergantung pada efektivitas dari terapi yang diberikan. Kondisi di lapangan menunjukkan tidak semua pasien PPOK memberikan respon positif terhadap pengobatan. Sebuah studi terkait evaluasi penggunaan bronkodilator dan kortikosteroid pada pasien PPOK di RSUP Fatmawati pada tahun 2016 menunjukkan bahwa tidak ada perbedaan yang signifikan pada nilai $\mathrm{PaCO}_{2}$ dan $\mathrm{PaO}_{2}$ pasien PPOK antara sebelum dan sesudah terapi $(\mathrm{p}=0,645 ; \mathrm{p}$ $=0,209$ ) (Sugiharta, 2016). Studi pendahuluan lain di tahun 2019 terkait efektivitas penggunaan bronkodilator dan kortikosteroid juga menunjukkan bahwa rata-rata lama rawat inap (AvLOS) pasien PPOK di rumah sakit adalah 11,4 hari (Veryanti \& Wulandari, 2020b). Angka ini melebihi standar yang ditetapkan Kementrian Kesehatan Republik Indonesia, dimana seharusnya tidak lebih dari 9 hari (Kementerian Kesehatan RI, 2011). Berdasarkan data tersebut dapat diketahui bahwa masih ditemukan adanya permasalahan terkait efektivitas terapi pada pasien PPOK. Setelah kita mengetahui efektivitas terapi pasien, selanjutnya kita dapat melakukan identifikasi permasalahan terkait obat yang menjadi penyebab ketidak-efektivan terapi tersebut. Melalui upaya tersebut, diharapkan akan terjadi peningkatan penggunaan obat secara rasional sehingga bisa menurunkan angka morbiditas dan mortalitas PPOK (Riley \& Sciurba, 2019).

Selain $\mathrm{PaCO}_{2}, \mathrm{PaO}_{2}$, dan AvLOS, ada beberapa parameter lainnya yang juga penting untuk dimonitoring guna mengevaluasi efektivitas terapi yang diberikan pada pasien PPOK. Arus Puncak Ekspirasi (APE) adalah salah satunya. APE merupakan ekspirasi maksimum selama satu manuver paksa sehingga dapat digunakan untuk mengukur fungsi jalan udara (Kementerian Kesehatan RI, 2015). Pada pasien PPOK, nilai 
APE pada umumnya kurang dari normal, yaitu $<500 \mathrm{~L} /$ menit untuk laki-laki dan $<380$ L/menit untuk perempuan. Berkurangnya nilai APE ini sebagai akibat dari adanya penyempitan pada jalan napas. Terapi bronkodilator dan kortikosteroid dapat dikatakan efektif bila terjadi peningkatan nilai APE minimum sebesar $15 \%$ dari APE awal saat pasien di rawat (Kementerian Kesehatan RI, 2015).

Berdasarkan uraian di atas, penting untuk dilakukan penelitian terkait efek terapi bronkodilator dan kortikosteroid terhadap perubahan nilai APE pasien PPOK. Penelitian ini dapat memberikan gambaran perubahan APE pasien PPOK antara sebelum dan setelah pemberian terapi bronkodilator dan kortikosteroid.

\section{MetodePenelitian}

Penelitian ini merupakan penelitian dreskriptif dengan pendekatan cross sectional. Penelitian dilakukan di RSUP Persahabatan Jakarta dengan mengambil data sekunder berupa data rekam medik pasien periode Januari-Desember 2018. Adapun jumlah rekam medik yang digunakan sebagai sampel adalah sebanyak 99. Dalam pemilihan sampel, digunakan teknik purposive sampling dengan kriteria inklusi dan eksklusi yang telah ditentukan sebelumnya. Kriteria inklusi pada penelitian ini adalah rekam medik pasien yang didiagnosa PPOK serta mendapatkan terapi bronkodilator dan kortikosteroid. Pasien mendapatkan terapi sesuai dengan derajat keparahan PPOK. Pasien dengan derajat berat diberikan terapi bronkodilator kombinasi inhalasi dan intravena serta ditambahkan kortikosteroid. Sedangkan untuk derajat sedang diberikan bronkodilator inhalasi dan kortikosteroid. Bronkodilator yang digunakan adalah salbutamol, ipatropium bromida (inhalasi/nebul) dan aminofilin (intravena). Kortikosteroid yang digunakan adalah budesonide dan metilprednisolon. Data rekam medik yang tidak lengkap dieksklusi dari penelitian. Data yang diambil meliputi data karakteristik pasien (usia, jenis kelamin, tingkat keparahan penyakit dan gejala/keluhan saat masuk rumah sakit), jenis obat bronkodilator dan kortikosteroid yang digunakan serta nilai APE awal dan akhir pasien. Selanjutnya data diolah dan dianalisis dengan menggunakan uji t-berpasangan untuk mengetahui perbedaan perubahan nilai APE pasien sebelum dan sesudah terapi.

\section{Hasil dan Pembahasan}

Hasil penelitian menunjukkan bahwa sebagian besar pasien yang mengalami PPOK berjenis kelamin laki-laki $(91,92 \%)$. Tingginya angka kejadian pada laki-laki berkaitan dengan kebiasaan merokok. Asap rokok diketahui sebagai faktor resiko utama penyebab terjadinya PPOK. Data Riskesdas (2013) juga menunjukkan bahwa proporsi kebiasaan merokok pada laki-laki berusia $\geq 15$ tahun jauh lebih besar dibandingkan dengan perempuan yaitu, 64,9\% berbanding 2,1\% (Kementerian Kesehatan RI, 2013). Kandungan nikotin dan zat iritan lainnya pada rokok dapat mengaktifkan makrofag dan sel epitel di saluran pernapasan sehingga menyebabkan lepasnya mediator inflamasi. Inflamasi kronik yang terjadi pada saluran pernapasan dapat menyebabkan terjadinya emfisema dan menstimulasi peningkatan sekresi mukus yang menyebabkan obstruksi jalan napas (Saminan, 2016). Karakteristik pasien berdasarkan usia dalam penelitian ini menunjukkan bahwa kejadian PPOK meningkat seiring dengan bertambahnya usia. Dengan bertambahnya usia, khususnya di atas 54 tahun, kekuatan otot, fungsi paru dan 
daya tahan kardiorespirasi akan mengalami penurunan (Global Initiative for Chronic Obstructive Lung Disease, 2021). Penelitian di RSUP Prof.R.D Kandou Manado juga menunjukkan hasil yang sama, dimana sebagian besar pasien PPOK berusia 56-65 tahun $(43,33 \%)$ (Hathasary, Wiyono, \& Mpila, 2021). Pada penelitian ini juga terlihat adanya penurunan angka kejadian PPOK untuk pasien $\geq 65$ tahun. Penurunan ini berkaitan dengan tingginya angka kematian lansia di atas 65 tahun. Sebuah penelitian menunjukkan bahwa 11,23\% kematian lansia $\geq 65$ tahun disebabkan oleh PPOK dan angka ini merupakan tertinggi kedua setelah stroke. Sebagian besar kematian akibat PPOK (>70\%) terjadi di rumah, sehingga terlihat adanya trend penurunan pasien PPOK yang di rawat di rumah sakit di atas 64 tahun (Simarmata, Lolong, Pangaribuan, Sulistiyowati, \& Sulistiowati, 2018)

Semua pasien PPOK yang dirawat di RSUP Persahabatan Jakarta datang dengan keluhan sesak napas dan $86,87 \%$ diantaranya disertai batuk. Sesak napas dan batuk yang dialami pasien tersebut diakibatkan oleh obstruksi saluran pernapasan yang terjadi secara kronik (Saminan, 2016). Jika dilihat dari tingkat keparahan penyakit, pasien PPOK yang di rawat memiliki derajat PPOK dari sedang hingga sangat berat. Berdasarkan hasil pengukuran spirometri, derajat PPOK sedang ditandai dengan nilai Forced Expiratory Volume in one second $\left(\mathrm{FEV}_{1}\right)$ antara $\leq 50 \%$ sampai $<80 \%$, sedangkan untuk kasus berat nilai $\mathrm{FEV}_{1}$ diantara $\leq 30 \%$ sampai $<50 \%$, dan sangat berat memiliki nilai $\mathrm{FEV}_{1}<30 \%$ (Global Initiative for Chronic Obstructive Lung Disease, 2021). Pada kasus PPOK dengan derajat sedang, pasien mulai menunjukkan adanya perburukan hambatan aliran udara sehingga mulai mencari pengobatan. Sedangkan pada kasus yang lebih berat, pasien menunjukkan gejala sesak napas yang semakin berat dan terjadi eksaserbasi akut. Jika hal ini tidak segera ditangani dapat menyebabkan terjadinya gagal napas dan kematian. Oleh karena itu untuk kasus PPOK dengan derajat berat akan lebih banyak ditemui di rumah sakit, sedangkan untuk derajat ringan akan ditangani di fasilitas kesehatan tingkat 1 seperti puskesmas atau klinik (Kementerian Kesehatan RI, 2015). Karakteristik pasien PPOK di RSUP Persahabatan Jakarta ditampilkan pada tabel 1.

Tabel 1. Karakteristik Pasien PPOK di RSUP Persahabatan Jakarta

\begin{tabular}{cccc}
\hline \multirow{2}{*}{ Parameter } & Karakteristik & $\begin{array}{c}\text { Jumlah } \\
(\mathbf{n})\end{array}$ & $\begin{array}{c}\text { Persentase } \\
(\mathbf{\%})\end{array}$ \\
\cline { 2 - 4 } Usia (Tahun) & & 0 & 0 \\
\hline & $26-34$ & 1 & 1,02 \\
\hline & $35-44$ & 15 & 15,15 \\
\hline & $45-54$ & 38 & 38,38 \\
\hline & $55-64$ & 24 & 24,24 \\
\hline Jenis Kelamin & $65-74$ & 21 & 21,21 \\
\hline & $\geq 75$ & 99 & 100 \\
\hline & Total & & \\
\hline & Laki-Laki & 91 & 91,92 \\
\hline Derajat PPOK & Perempuan & 8 & 8,08 \\
\hline
\end{tabular}




\begin{tabular}{cccc}
\hline \multirow{2}{*}{ Parameter } & Parakteristik & $\begin{array}{c}\text { Jumlah } \\
(\mathbf{n})\end{array}$ & $\begin{array}{c}\text { Persentase } \\
(\mathbf{\%})\end{array}$ \\
\cline { 2 - 4 } & Ringan & 0 & 0 \\
\hline Sedang & 32 & 32,32 \\
\hline Berat & 54 & 54,55 \\
\hline Gejala & Sangat Berat & 13 & 13,13 \\
\hline & Total & 99 & 100 \\
\hline & & 13,13 \\
\hline & Sesak Napas & 13 & $86,87 \%$ \\
\hline & Sesak Napas dan Batuk & 86 & 100 \\
\hline
\end{tabular}

Untuk mengatasi permasalahan pada jalur pernapasan, pasien diterapi dengan bronkodilator dan kortikosteroid. Bronkodilator yang digunakan di RSUP Persahabatan Jakarta adalah kombinasi salbutamol dan ipratropium serta aminofilin, sedangkan untuk golongan kortikosteroid yang digunakan adalah budesonide dan metilprednisolon. Pasien diberikan terapi sesuai dengan tingkat keparahan penyakit. Pasien PPOK dengan derajat berat mendapat terapi bronkodilator dengan rute pemberian kombinasi inhalasi dan intravena sedangkan derajat sedang hanya diberikan bronkodilator inhalasi saja. Namun kedua kelompok pasien tersebut sama-sama diberikan kortikosteroid sebagai antiinflamasi. Kombinasi kedua obat ini dapat memberi keuntungan karena bekerja secara sinergis. Bronkodilator mengaktifkan reseptor beta 2 sehingga dapat merelaksasi otot-otot pernapasan, melebarkan jalur udara dan aliran udara ke paru-paru menjadi lancar (Perhimpunan Dokter Paru Indonesia, 2011). Kortikosteroid merupakan antiinflamasi yang terbukti dapat meningkatkan fungsi paru dan oksigenasi pada pasien PPOK (Veryanti \& Wulandari, 2020a).

Efek penggunaan bronkodilator dan kortikosteroid pada pasien PPOK dapat dilihat pada tabel 2 .

Tabel 2. Perbandingan Nilai Arus Puncak Ekspirasi (APE) Pasien PPOK Sebelum dan Sesudah Terapi

\begin{tabular}{ccccc}
\hline \multirow{2}{*}{ Parameter } & \multicolumn{4}{c}{ Terapi Bronkodilator dan Kortikosteroid } \\
\cline { 2 - 5 } & Sebelum & Sesudah & Perubahan $(\Delta)$ & p-value \\
\hline $\begin{array}{c}\text { Nilai APE Rata-Rata } \\
\text { (L/menit) }\end{array}$ & $136,97 \pm 51,32$ & $186,82 \pm 60,32$ & $49,85 \pm 43,61$ & $0,000^{*}$ \\
\hline Persentase (\%) & & & $46,05 \pm 51,15$ & \\
\hline
\end{tabular}

*uji t-berpasangan

Berdasarkan tabel 2 diketahui bahwa penggunaan bronkodilator dan kortikosteroid pada pasien PPOK dengan derajat sedang sampai sangat berat dapat meningkatkan Arus Puncak Ekspirasi (APE) pasien secara signifikan $(\mathrm{p}=0,000)$. Terdapat variasi nilai APE pada pasien PPOK baik sebelum maupun sesudah terapi. Hal ini disebabkan oleh adanya perbedaan tingkat keparahan PPOK. Pasien dengan derajat keparahan berat memiliki nilai APE jauh di bawah normal, sedangkan untuk pasien dengan derajat keparahan sedang memiliki APE yang lebih besar dari pasien dengan derajat berat namun tetap berada di bawah normal. Selain hal tersebut, perbedaan jenis kelamin juga menjadi penyebab 
besarnya simpangan baku (nilai SD) pada nilai rata-rata APE pasien PPOK dalam penelitian ini. Nilai APE normal untuk laki-laki adalah 500-700 L/menit sedangkan untuk perempuan adalah 380-500 L/menit (Kementerian Kesehatan RI, 2015).

Walaupun nilai akhir APE pasien pada penelitian belum mencapai normal, namun rata-rata peningkatannya mencapai $46,05 \pm 51,15 \%$. Menurut Kementerian Kesehatan Republik Indonesia (2015), terapi PPOK dinyatakan efektif bila dapat meningkatan nilai APE pasien minimal 15\% (Kementerian Kesehatan RI, 2015). Jumlah pasien dengan nilai APE yang mencapai target terapi (peningkatan $\geq 15 \%$ ) ditampilkan pada tabel 3 .

Tabel 3. Perubahan Nilai Arus Puncak Ekspirasi (APE) Pasien PPOK setelah diberi terapi di RSUP Persahabatan Jakarta

\begin{tabular}{ccc}
\hline Parameter & Jumlah (n) & Persentsae (\%) \\
\hline Kondisi Akhir Pasien & & \\
\hline Peningkatan APE (\%) & 94 & 94,95 \\
\hline Tetap & 2 & 2,02 \\
\hline Penurunan APE (\%) & 3 & 3,03 \\
\hline Total & 99 & 100 \\
\hline Perubahan APE (\%) & & \\
\hline$\geq 15$ & 73 & 73,74 \\
\hline$\leq 15$ & 26 & 26,26 \\
\hline Total & 99 & 100
\end{tabular}

Berdasarkan tabel 3 dapat diketahui bahwa sebagian besar pasien $(94,05 \%)$ mengalami peningkatan nilai APE dan sebanyak 73,74\% diantaranya mengalami peningkatan lebih dari $15 \%$. Hasil penelitian ini sejalan dengan Mirici et al. (2012) yang membandingkan efektivitas kortikosteroid budesonide nebul dengan prednisolon intravena pada pasien PPOK. Penelitian tersebut menunjukkan bahwa kedua terapi kortikosteroid tersebut sama-sama dapat meningkatkan nilai APE pasien PPOK secara signifikan $(\mathrm{p}<0,001)$ (Mirici, Meral, \& Akgun, 2003). Penelitian mengenai efektivitas bronkodilator pada pasien PPOK juga dilakukan oleh Reisner et al pada tahun 2012, dimana dihasilkan bahwa penggunaan kombinasi Long-Acting Muscarinis Antganoists (LAMA) dan Long Acting 32 -Agonists (LABA) dalam bentuk dosis tetap pada pasien PPOK, signifikan meningkatkan APE pasien $(\mathrm{p}<0,005)$ (Reisner dkk., 2012). Hasil penelitian ini mengindikasikan bahwa terapi bronkodilator dan kortikosteorid memberikan efek positif terhadap perubahan nilai APE pasien PPOK yang di rawat di RSUP Persahabatan Jakarat Periode tahun 2018.

\section{Kesimpulan}

Berdasarkan hasil penelitian yang diperoleh, maka dapat disimpulkan bahwa pemberian bronkodilator dan kortikosteroid pada pasien PPOK memberikan efek yang signifikan terhadap perubahan nilai APE pasien $(\mathrm{p}=0,000)$. Rata-rata peningkatan nilai

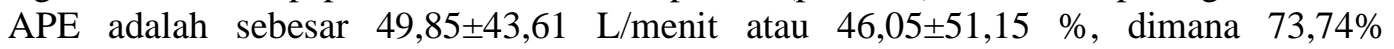
diantaranya mengalami peningkatan nilai $\mathrm{APE} \geq 15 \%$. 


\section{Referensi}

Global Initiative for Chronic Obstructive Lung Disease. (2021). Global Strategy for the Diagnosis, Management, and Prevention of Chronic Obstructive Pulmonary Disease 2021 Report (hlm. 164).

Hathasary, R. H., Wiyono, W., \& Mpila, D. A. (2021). Evaluasi Penggunaan Obat pada Pasien Ppok (Penyakit Paru Obstruktif Kronis) di Instalasi Rawat Jalan RSUP Prof. Dr. R.D. Kandou Manado. PHARMACON, 10(1), 630-638. https://doi.org/10.35799/pha.10.2021.32748

Kementerian Kesehatan RI. (2011). Modul Penggunaan Obat Rasional. Jakarta: Kementerian Kesehatan RI.

Kementerian Kesehatan RI. (2013). Laporan Nasional Riskesdas 2013. Jakarta: Badan Penelitian dan Pengembangan Kesehatan Kementerian Kesehatan RI.

Kementerian Kesehatan RI. (2015). Petunjuk Teknis Penerapan Pendekatan Praktis Kesehatan Paru di Indonesia. Jakarta: Direktorat Jenderal Pengendalian Penyakit dan Penyehatan Lingkungan Kementerian Kesehatan RI.

Mirici, A., Meral, M., \& Akgun, M. (2003). Comparison of the Efficacy of Nebulised Budesonide with Parenteral Corticosteroids in the Treatment of Acute Exacerbations of Chronic Obstructive Pulmonary Disease. Clinical Drug Investigation, 23(1), 55-62. https://doi.org/10.2165/00044011-20032301000007

Perhimpunan Dokter Paru Indonesia. (2011). Penyakit Paru Obstruktif Kronik (PPOK) Edisi Buku Lengkap, Pedoman Diagnosis Dan Penatalaksanaan di Indonesia. Jakarta.

Reisner, C., Rennard, S. I., Forgaty, C., Fischer, T., St Rose, E., Fernandez, C., \& Orevillo, C. (2012). Pearl Therapeutics' Combination LAMA/LABA MDI (GFF-MDI, PT003) Provides A Significant Benefit On Home Peak Expiratory Flow Rate (PEFR) And Reduces The Need For Rescue Albuterol Use Compared To Its Components Administered Alone, Spiriva ${ }^{\circledR}$ Handihaler ${ }^{\circledR}$, And Foradil ${ }^{\circledR}$ Aerolizer ${ }^{\circledR}$ In A Randomized, Double-Blind, Placebo-Controlled Phase 2b Study In Patients With COPD | A101. PHARMACOLOGICAL TREATMENT OF COPD: OLD AND NEW. American Thoracic Society International Conference Meetings Abstracts. (world). https://doi.org/10.1164/ajrccmconference.2012.185.1_MeetingAbstracts.A2259

Riley, C. M., \& Sciurba, F. C. (2019). Diagnosis and Outpatient Management of Chronic Obstructive Pulmonary Disease: A Review. JAMA, 321(8), 786-797. https://doi.org/10.1001/jama.2019.0131

Saminan, S. (2016). Efek Perilaku Merokok Terhadap Saluran Pernapasan. Jurnal Kedokteran Syiah Kuala, 16(3), 191-194.

Simarmata, O. S., Lolong, D. B., Pangaribuan, L., Sulistiyowati, N., \& Sulistiowati, E. (2018). Penyebab Kematian di Kabupaten Gianyar Tahun 2010-2012. Buletin Penelitian Kesehatan, 46(2), 77-86. https://doi.org/10.22435/bpk.v46i2.7 
Sugiharta, S. (2016). Evaluasi Pengobatan Bronkodilator Dan Kortikosteroid Pada Pasien PPOK Di Instalasi Rawat Inap B RSUP Fatmawati Jakarta Periode Januari 2012-Juni 2013. SOCIAL CLINICAL PHARMACY INDONESIA JOURNAL, $1(1), 76-88$.

Veryanti, P. R., \& Wulandari, A. (2020a). Analisis Efektivitas Biaya Penggunaan Bronkodilator dibandingkan Kombinasi Bronkodilator-Kortikosteroid pada Pasien Penyakit Paru Obstruktif Kronik (PPOK). Jurnal Farmasi Udayana, 1318. https://doi.org/10.24843/JFU.2020.v09.i01.p02

Veryanti, P. R., \& Wulandari, A. (2020b). Effectiveness of Bronchodilator and Corticosteroid Treatment in Patients with Chronic Obstructive Pulmonary Disease (COPD). Journal of Pharmaceutical Science and Application, 2(1), 1722. https://doi.org/10.24843/JPSA.2020.v02.i01.p03 